\title{
Diversity of lactic acid bacteria isolated during fermentation of indigenous cassava obtained from Sumba, East Nusa Tenggara, Indonesia
}

\author{
IMMANUELLA BERLIANA ELVANI HUTAJULU ${ }^{1}$, PERISKILA DINA KALI KULLA ${ }^{1}$, \\ ENDAH RETNANINGRUM ${ }^{2, \varphi}$ \\ ${ }^{1}$ Graduate Program, Faculty of Biology, Universitas Gadjah Mada. Jl. Teknika Selatan, Sekip Utara, Sleman 55281, Yogyakarta, Indonesia \\ ${ }^{2}$ Microbiology Laboratory, Faculty of Biology, Universitas Gadjah Mada. Jl. Teknika Selatan, Sekip Utara, Sleman 55281, Yogyakarta, Indonesia. \\ Tel./fax.: +62-274-580839, `email: endahr@ugm.ac.id
}

Manuscript received: 6 December 2020. Revision accepted: 5 June 2021.

\begin{abstract}
Hutajulu IBE, Kulla PDK, Retnaningrum E. 2021. Diversity of lactic acid bacteria isolated during fermentation of indigenous cassava obtained from Sumba, East Nusa Tenggara, Indonesia. Biodiversitas 22: 2561-2570. Traditional fermented food products hold a great significance in the routine diet of Indonesian inhabitants. The present study investigated the diversity of lactic acid bacteria (LAB) found in fermented indigenous cassava, ubi karet busuk, produced in Sumba, East Nusa Tenggara, Indonesia. The isolated LAB was characterized for their phenotypic, biochemical, and molecular traits, which involved 16S rRNA gene sequencing, determination of lactic acid fermentation pathway, and measurement of $\beta$-glucosidase and tannase activity in the LAB strains. During fermentation, 15 LAB strains were obtained from the cassava. Among these, $93.33 \%$ strains were found to be homofermentative, whereas $6.73 \%$ strains displayed heterofermentative traits. BLASTn and phylogenetic analysis classified 15 LAB strains into six species, namely Enterococcus faecium, Enterococcus faecalis, Enterococcus casseliflavus, Leuconostoc mesenteroides, Lactococcus lactis, and Enterococcus sp. Among these, $10 \mathrm{LAB}$ strains displayed $\beta$-glucosidase activity, with highest enzyme activity of $7.13 \mathrm{U} / \mathrm{mL}$ recorded in L. lactis F14IS3. Interestingly, two of these strains also showed expression of tannase, with F6IS1 strain displaying highest enzyme activity of 38.23 $\mathrm{U} / \mathrm{mL}$. Thus, the study results highlighted the suitability of these $\beta$-glucosidase and tannase-producing LAB strains to be used as a starter in the fermentation of cassava and other substrates such as vegetables, fruits, and legumes. These strains can also be utilized in animal feed, food, and beverage industries.
\end{abstract}

Keywords: $\beta$-glucosidase, homofermentative, tannase, phylogenetic analysis, $16 \mathrm{~S}$ rRNA gene

\section{INTRODUCTION}

In Indonesia, a variety of traditional fermented food products have been in use since ancient times. These fermented products constitute an integral part of daily diet of Indonesian people. Among these, ubi karet busuk is the most famous traditional fermented cassava produced in Sumba Island, East Nusa Tenggara, Indonesia. The production of ubi karet busuk uses cassava as a substrate and involves solid-state fermentation with natural microorganisms, present on the cassava and surrounding environment, for two weeks. This product is sun-dried to ensure long storage life. It displays distinct physical characteristics, such as chewy texture, black color, and dry nature. The process of fermentation prevents post-harvest deterioration of the cassava (Kulla and Retnaningrum 2019).

Among the various microorganisms involved in the fermentation process of ubi karet busuk, lactic acid bacteria (LAB) is the most common natural microbe that plays an important role in the inhibition of growth for both spoilage and pathogenic microorganisms, and thus act as major players in preventing the deterioration of the cassava. During the fermentation process, LAB has been reported to produce organic acid and various antimicrobial compounds, including hydrogen peroxide, antibiotics, reuterin, and bacteriocins, that are known to exert inhibitory effect on both the spoilage and pathogenic bacteria (Delpech et al. 2015; Langa et al. 2018; Nurhikmayani et al. 2019; Sapalina and Retnaningrum 2020; Retnaningrum et al. 2020). In addition to this, certain enzymes are also released during lactic acid fermentation process. These enzymes hydrolyze the chemical compounds present in the cassava to generate products with desired texture and enhanced flavor, while reducing the unsatisfactory and anti-nutritional components such as cyanogen and tannin (Freire et al. 2015)

During the fermentation of cassava, several LAB strains have been reported to produce tannase and $\beta$-glucosidase that act on cyanogen and tannins, respectively, to reduce their concentration (Acebrón et al. 2017; Liu et al. 2018; Kanpiengjai et al. 2019; Shang et al. 2019). Tannins are polyphenolic compounds that are divided into two categories, hydrolyzable tannins (HT) and condensed tannins (CT). Generally, tannins are naturally occurring water-soluble polyphenols with molecular weights in the range of 500$3000 \mathrm{Da}$, which is largely dependent on the chemical bonds possessed by proteins and polysaccharides. The tannins present in the cassava are responsible for its unpleasant taste and astringent aroma. In comparison to this, cyanogens are the toxic compounds present in cassava that 
induce serious side-effects in the body, including vomiting, nausea, dizziness, stomach pain, weakness, headache, diarrhea, and sometimes even death (Nambisan 2011).

Sumba Island is known to have a long dry season of eight months (April-November) and a very short rainy season of four months (December-March). During the dry season, crop failure owing to drought conditions poses a serious challenge. Processing of cassava by fermentation is widely practiced by the inhabitants of Sumba Island and the resulting product, ubi karet busuk, provides food security during dry season. Currently, no information is available regarding the diversity of LAB present in $u b i$ karet busuk. Thus, the present study aimed to investigate the diversity of LAB that plays an important role in the fermentation of ubi karet busuk. In particular, the properties of lactic acid fermentation were characterized and the production of tannase and $\beta$-glucosidase was measured in LAB strains. The study results would aid in identifying the strains that could be used as a starter in the fermentation of cassava and other food sources like fruits and vegetables.

\section{MATERIALS AND METHODS}

\section{Sample, medium, and chemicals}

The samples for ubi karet busuk were collected from the inhabitants of East Nusa Tenggara of Sumba Island, who were actively involved in the production of fermented cassava. Medium of Man Rogosa Sharpe Agar (MRSA) and Man Rogosa Sharpe Broth (MRSB) were used for isolating and characterizing the LAB. The Quick-DNA ${ }^{\mathrm{TM}}$ Fungal/Bacterial Miniprep Kit, Zymo Research was used to extract genomic LAB. Para-nitrophenyl- $\beta$-D-glucopyranoside ( $p$ NPG) and methyl gallate were utilized as substrates in the enzyme reaction to determine the activity of $\beta$ glucosidase and tannase in LAB strain, respectively.

\section{Sampling and Isolation of LAB}

Five samples of ubi karet busuk were collected during the fermentation process at pre-defined time intervals, particularly at $0,2,4,6$, and 14 days of incubation. Post sample collection, $10 \mathrm{~g}$ of the sample was suspended in 90 $\mathrm{mL}$ of sterile physiological solution, homogenized for 3 min, and serially diluted to obtain concentrations in the range of $10^{-5}$ to $10^{-8}$. Further, $0.1 \mathrm{~mL}$ of the diluted sample was inoculated onto Man Rogosa Sharpe Agar (MRSA) medium containing $1 \%(\mathrm{w} / \mathrm{v}) \mathrm{CaCO}_{3}$, using pour plate method. The plates were incubated at $37^{\circ} \mathrm{C}$ for $48-96$ hours. For each sample, colonies that formed clear zones were selected as LAB.

\section{Identification LAB strains based on phenotypic properties}

In order to identify the phenotypic properties, the isolates were assessed for their morphological and biochemical traits. The morphological characteristics of LAB were evaluated on the basis of the morphology of the colonies as well as cells, which involved gram staining. Further, the biochemical characteristics of LAB were defined in terms of their motility and ability to produce catalase. Additionally, the fermentation profile of the isolates in Man Rogosa Sharpe Broth (MRSB) medium supplemented with various sugar sources such as glucose and pentose (xylose, arabinose and ribose) was also evaluated. The fermentation profile of these LAB strains was determined in terms of their fermentation products, like organic acids (lactic acid, acetic acid, propionic acid) and ethanol, which were analyzed using high-performance liquid chromatography (HPLC). The rise of the Durham tube carrying the $\mathrm{CO}_{2}$ gas product towards the top of the culture was used to study the heterofermentative capabilities of the LAB strain in creating $\mathrm{CO}_{2}$.

In order to monitor the fermentation profile of LAB strains, the bacterial isolates were first inoculated in MRSB medium supplemented with a variety of sugar sources for 48 hours to achieve desired cell density of $10^{7} \mathrm{CFU} / \mathrm{mL}$. Following this, the LAB culture was heated to $80^{\circ} \mathrm{C}$ in a water bath, resulting in microorganisms and protein precipitation inactivation. The sample was centrifuged at $4000 \mathrm{rpm}, 4^{\circ} \mathrm{C}$ for $10 \mathrm{~min}$ and $1.5 \mathrm{~mL}$ of the resulting supernatant was transferred to a fresh tube. The supernatant was further centrifuged at $20,800 \times \mathrm{g}$ for $3 \mathrm{~min}$ to obtain a clear solution. In order to detect the presence of lactic acid, acetic acid, propionic acid, and ethanol in the clear solution, HPLC analysis (Knauer) was performed on a Zorbax C-18 column $(250 \mathrm{~mm} \times 4.6 \mathrm{~mm})$ with diode array detector at $210 \mathrm{~nm}$ and flow rate of $0.5 \mathrm{~mL} / \mathrm{min}$. The mobile phase used for HPLC separation comprised of 0.01 $\mathrm{mol} / \mathrm{L} \mathrm{KH}_{2} \mathrm{PO}_{4}-\mathrm{H}_{3} \mathrm{PO}_{4}(\mathrm{pH} 2.6)$ and $3 \%$ methanol (v/v). To measure the production of organic acids, an external standard approach established by Vilanova and co-workers was used (Vilanova et al. 2014).

\section{Molecular identification of LAB strains using $16 \mathrm{~S}$ rRNA gene}

Genomic DNA of LABl strains was extracted using the Quick-DNA $^{\mathrm{TM}}$ Fungal/Bacterial Miniprep Kit, Zymo Research, according to the manufacturer's instructions. Further, the extracted DNA was used to amplify 16S rRNA gene using universal 16S rRNA primers, 27F (5'-AGAGTTTGATCMTGGCTCAG-3') and 1492R (5'-TACGGYTACCTTGTTACGACTT-3'). PCR amplification was performed in a thermal PCR cycler. The PCR products were separated on a $1 \%$ agarose gel by electrophoresis. The bands corresponding to PCR products were extracted, purified, and subjected to Sanger sequencing (Sanger et al. 1977). Further, the sequencing results were validated using Basic Local Alignment Search Tool for nucleotide (BLASTn) located on the National Center for Biotechnology Information (NCBI) (http://www.ncbi.nlm.nih.gov). In addition to this, sequencing data were aligned using ClustalW software, and Kimura two-parameter (K2P) method was used to calculate the genetic differences (Kimura 1980). Maximum Likelihood method was used to establish phylogenetic relationships and a phylogenetic tree was generated. Bootstrap study involving 1000 resampling was used to estimate the confidence interval of tree topologies. MEGA X software was used for phylogenetic analysis (Kumar et al. 2018) 
Evaluation of $\beta$-glucosidase and tannase activity of LAB strains

To evaluate $\beta$-glucosidase activity of LAB strains, para-nitrophenyl- $\beta$-D-glucopyranoside ( $p N P G)$ was used as substrate (Weagant et al. 2001). Each LAB strain was grown overnight in $250 \mathrm{~mL}$ MRSB medium and centrifuged at $6000 \times \mathrm{g}$ for $10 \mathrm{~min}$ at $4^{\circ} \mathrm{C}$. The cell pellet was washed twice and re-suspended in $1 \mathrm{~mL}$ phosphate buffered saline (PBS). Further, $\beta$-glucosidase activity was determined by mixing $0.2 \mathrm{~mL}$ of the bacterial suspension containing $10^{7} \mathrm{CFU} / \mathrm{mL}$ and $0.4 \mathrm{~mL}$ of $5 \mathrm{mM} p$ NPG. The sample was incubated at $37^{\circ} \mathrm{C}$ for $30 \mathrm{~min}$, and the reaction was stopped by the addition of $0.8 \mathrm{~mL}$ of $1 \mathrm{M} \mathrm{Na}_{2} \mathrm{CO}_{3}$ (Donkor and Shah 2008). The assay works on the principle that the presence of $\beta$-glucosidases in the sample catalyzes the conversion of $p$ NPG to p-nitrophenol ( $p$ NP). Further, the amount of $p N P$ released in the supernatant was measured at $405 \mathrm{~nm}$ using an ultraviolet-visible (UV-Vis) spectrophotometer. Here, one unit of enzyme activity was defined as the amount of $\beta$-glucosidase that produced 1 $\mu \mathrm{mol}$ of $p \mathrm{NP}$ per minute under the assay conditions (Otieno et al. 2006).

Next, the tannase activity of LAB strains was measured using methanolic rhodanine methodology previously described by Sharma et al. (2000). This method involves formation of a chromogen between gallic acid (released by the action of tannase on propyl gallate) and rhodanine (2-thio-4-ketothiazo-lidine). The assay was performed using bacterial culture containing $10^{7} \mathrm{CFU} / \mathrm{mL}$. To prepare bacterial culture, one loop of LAB culture was taken on MRS agar plate, which was further transferred to $1 \mathrm{~mL}$ of substrate medium ( $\mathrm{pH}$ 5.0) containing $33 \mathrm{mM} \mathrm{NaH}{ }_{2} \mathrm{PO}_{4}$ and $20 \mathrm{mM}$ methyl gallate. The substrate medium was further incubated at $37^{\circ} \mathrm{C}$ for $24 \mathrm{~h}$. Post incubation, the sample was alkalinized using an equal amount of saturated $\mathrm{NaHCO}_{3}$ solution ( $\mathrm{pH} 8.6$ ), and it was exposed to the atmosphere for $1 \mathrm{~h}$ at room temperature. To prepare crude enzyme extract, LAB culture was centrifuged at $6000 \times \mathrm{g}$ for $10 \mathrm{~min}$ at $4^{\circ} \mathrm{C}$. Further, the absorbance of the crude enzyme sample was measured using spectrophotometer at a wavelength of $530 \mathrm{~nm}$ (Mondal et al. 2001). One unit of tannase activity was defined as the amount of tannase that hydrolyzed $1 \mu \mathrm{mol}$ of substrate tannic acid in one minute under the assay conditions.

\section{RESULTS AND DISCUSSION}

\section{Isolation and phenotypic identification of LAB isolated from ubi karet busuk}

During the fermentation process, a total of six ubi karet busuk samples were collected, at pre-defined time points covering the initial period (0 days), middle period (2, 4, and 6 days), and final period (14 days). The collected samples were processed and inoculated on MRSA medium supplemented with $1 \%(\mathrm{v} / \mathrm{v}) \mathrm{CaCO}_{3}$. After incubation for 48-96 h, 23 bacterial colony strains showing clear zones on MRS agar plates were selected and predicted as LAB. The results for the isolated strains are summarized in Table 1. In general, the formation of the clear zone on the agar plates is contributed by the production of organic acids by bacterial strains, which are endowed with the ability to dissolve $\mathrm{CaCO}_{3}$ into $\mathrm{Ca}$-lactate present in the medium. As shown in Table 2, all colony bacteria displayed the same shape, margins, and internal colony structure; however, they differed in color and colony elevation. Further evaluation of the biochemical characteristics resulted in the classification of 15 (out of 23) LAB strains as gram-positive, catalase-negative, and non-motile (Table 3). These results were in agreement with the findings of Axelsson (2004).

LAB strains were further classified as homofermentative and heterofermentative, based on the by-products of the fermentation process. In the present study, homofermentative trait was found to be predominating and $\sim 93.33 \%$ LAB strains isolated from indigenous cassava were associated with homofermentative trait, whereas only $6.73 \%$ LAB displayed heterofermentative character. Among the isolated strains, F2IS1, F2IS2, F4IS4, F4IS5, F6IS1, F6IS2, F6IS3, F6IS4, F6IS5, F14IS3, F14IS4, F14IS5, F14IS6, and F14IS7 strains showed homofermentative characteristic, while the heterofermentative trait was observed only in F14IS1 strain. All LAB strains could ferment glucose and xylose as a substrate, but showed no activity toward arabinose or ribose. Generally, homofermentative LAB strains catabolize glucose and pentose sugar via Embden-Meyerhof and pentose phosphate pathways to produce lactic acid as major product, more than $90 \%$ (Sauer et al. 2017; Hatti-Kaul et al. 2018). The results of the present study were in concordance with previous studies that reported several genera and species of homofermentative LAB, including Lactococcus, Enterococcus, Pediococcus, Lactobacillus delbruckii, Lactobacillus acidophilus, Lactobacillus helveticus, Lactobacillus casei, Lactobacillus plantarum, and Streptococcus salivarius (Grewal and Khare 2018; Hassan et al. 2019). In comparison to this, LAB displaying heterofermentative traits catalyzes lactic acid production and several other products, including acetic acid, propionic acid, ethanol, and $\mathrm{CO}_{2}$. In previous studies, LAB genera of Oenococcus and species of Weissella confuse, Weissella viridescens, Lactobacillus brevis, and Lactobacillus fermentum were categorized as heterofermentative (González-Arenzana et al. 2014; Fusco et al. 2015; Huang et al. 2018; Fabien et al. 2019; de la Fuente et al. 2021).

Table 1. Bacterial colony strains isolated during the fermentation of indigenous cassava obtained from Sumba, which formed clear zones on MRS agar plates

\begin{tabular}{cccc}
\hline \multicolumn{4}{c}{ LAB strain isolated during period of fermentation time (days) } \\
\hline $\mathbf{2}$ & $\mathbf{4}$ & $\mathbf{6}$ & $\mathbf{1 4}$ \\
\hline F2IS1 & F4IS1 & F6IS1 & F14IS1 \\
F2IS2 & F4IS2 & F6IS2 & F14IS2 \\
F2IS3 & F4IS3 & F6IS3 & F14IS3 \\
F2IS4 & F4IS4 & F6IS4 & F14IS4 \\
F2IS5 & F4IS5 & F6IS5 & F14IS5 \\
F2IS6 & & & F14IS6 \\
& & & F14IS7 \\
\hline
\end{tabular}


Table 2. Morphological characteristics of LAB strains obtained during the fermentation of indigenous cassava obtained from Sumba, Indonesia

\begin{tabular}{|c|c|c|c|c|c|c|c|}
\hline \multirow{2}{*}{ Strain } & \multicolumn{5}{|c|}{ Morphology of bacterial colonies } & \multicolumn{2}{|c|}{ Morphology of bacterial cells } \\
\hline & Shape & Color & Margin & Elevation & Internal structure & Shape & Gram staining \\
\hline F2IS1 & Circular & White & Entire & Flat & Smooth & Coccus & + \\
\hline F2IS2 & Circular & White & Entire & Flat & Smooth & Coccus & + \\
\hline F4IS4 & Circular & Grayish & Entire & Convex & Smooth & Coccus & + \\
\hline F4IS5 & Circular & White & Entire & Convex & Smooth & Coccus & + \\
\hline F6IS1 & Circular & White & Entire & Convex & Smooth & Coccus & + \\
\hline F6IS2 & Circular & White & Entire & Flat & Smooth & Coccus & + \\
\hline F6IS3 & Circular & White & Entire & Convex & Smooth & Coccus & + \\
\hline F6IS4 & Circular & White & Entire & Flat & Smooth & Coccus & + \\
\hline F6IS5 & Circular & White & Entire & Convex & Smooth & Coccus & + \\
\hline F14IS1 & Circular & White & Entire & Convex & Smooth & Coccus & + \\
\hline F14IS3 & Circular & White & Entire & Plateau & Smooth & Coccus & + \\
\hline F14IS4 & Circular & White & Entire & Convex & Smooth & Coccus & + \\
\hline F14IS5 & Circular & White & Entire & Convex & Smooth & Coccus & + \\
\hline F14IS6 & Circular & White & Entire & Flat & Smooth & Coccus & + \\
\hline F14IS7 & Circular & White & Entire & Convex & Smooth & Coccus & + \\
\hline
\end{tabular}

Table 3. Biochemical characteristics of LAB strains isolated during fermentation of indigenous cassava obtained from Sumba, Indonesia

\begin{tabular}{|c|c|c|c|c|c|c|c|}
\hline \multirow[t]{2}{*}{ Strain } & \multirow[t]{2}{*}{ Catalase } & \multirow[t]{2}{*}{ Motility } & \multicolumn{4}{|c|}{$\begin{array}{c}\text { Fermentation products of } \mathrm{LAB} \text { strains (lactic acid, acetic acid, } \\
\left.\text { propionic acid, ethanol, } \mathrm{CO}_{2}\right) \text { in various sugar }(\mathrm{mg} / \mathrm{mL})\end{array}$} & \multirow[t]{2}{*}{ Fermentation type } \\
\hline & & & Glucose & Xylose & Arabinose & Ribose & \\
\hline$\overline{\text { F2IS1 }}$ & - & Non-motile & LA (32) & $\mathrm{LA}(75)$ & - & - & Homofermentative \\
\hline F2IS2 & - & Non-motile & LA $(50)$ & LA(60) & - & - & Homofermentative \\
\hline F4IS4 & - & Non-motile & LA (30) & LA(50) & - & - & Homofermentative \\
\hline F4IS5 & - & Non-motile & LA (40) & LA(60) & - & - & Homofermentative \\
\hline F6IS1 & - & Non-motile & LA (60) & LA(70) & - & - & Homofermentative \\
\hline F6IS2 & - & Non-motile & LA (45) & LA(65) & - & - & Homofermentative \\
\hline F6IS3 & - & Non-motile & LA (35) & LA(55) & - & - & Homofermentative \\
\hline F6IS4 & - & Non-motile & LA (43) & LA(59) & - & - & Homofermentative \\
\hline F6IS5 & - & Non-motile & LA (38) & $\mathrm{LA}(57)$ & - & - & Homofermentative \\
\hline F14IS1 & - & Non-motile & $\begin{array}{l}\text { LA (40); AA (20); } \\
\text { Eth (15); G (+) }\end{array}$ & $\begin{array}{l}\text { LA (40); AA (20); } \\
\text { Eth }(15) ; \mathrm{G}(+)\end{array}$ & - & - & Heterofermentative \\
\hline F14IS3 & - & Non-motile & LA $(80)$ & $\mathrm{LA}(75)$ & - & - & Homofermentative \\
\hline F14IS4 & - & Non-motile & LA (48) & $\mathrm{LA}(50)$ & - & - & Homofermentative \\
\hline F14IS5 & - & Non-motile & LA (58) & $\mathrm{LA}(60)$ & - & - & Homofermentative \\
\hline F14IS6 & - & Non-motile & LA (52) & $\mathrm{LA}(65)$ & - & - & Homofermentative \\
\hline F14IS7 & - & Non-motile & LA (48) & $\mathrm{LA}(57)$ & - & - & Homofermentative \\
\hline
\end{tabular}

Note: +: positive result, ${ }^{-}$: negative result, LA: lactic acid, AA: acetic acid, PA; propionic acid, Eth: ethanol, G: $\mathrm{CO}_{2}$ gas

Lactic acid processing, especially by homofermentative LAB strains, finds wide applications in various industries, including food, beverage, cosmetic, pharmaceutical, and chemical industries. In addition to this, lactic acid production can be successfully carried out using a variety of inexpensive and abundant substrates, including food waste, starchy biomass and sugar plant wastes, dairy waste, and industrial waste (Sauer et al. 2017; Baruah et al. 2018; de Oliveira et al. 2018; Hatti-Kaul et al. 2018; Lopez-Gomez et al. 2019).

\section{Molecular identification of LAB isolated from ubi karet busuk using amplification of 16S rRNA gene}

To further confirm the results of phenotypic analysis, molecular identification of $15 \mathrm{LAB}$ strains was performed using PCR amplification of 16S rRNA gene. The $16 \mathrm{~S}$ rRNA gene was amplified using universal primers $27 \mathrm{~F}$ and 1492R. As shown in Figure 1, all bacterial isolates displayed strong amplification results and PCR products with size $\sim 1500$ bp were detected.

Nucleotide sequencing data for $16 \mathrm{~S}$ rRNA gene is the most suitable method for identifying microorganisms and establishing phylogenetic relationships among all microorganisms present on earth. Furthermore, the use of $16 \mathrm{~S}$ rRNA gene for identification purposes ensures accuracy due to certain unique characteristics. Importantly, this gene can be easily found in all organisms and its genetic sequences are moderately conserved, with conserved, variable, and hyper-variable regions. Besides this, 16S rRNA gene is only $1500 \mathrm{bp}$ in length, making it 
relatively simple to sequence and large enough to provide significant information required for the identification and phylogenetic analysis (Clarridge 2004).

The 16S rRNA gene sequences, obtained using Sanger sequencing, were compared with database at NCBI using Basic Local Alignment Search Tool Nucleotide (BLASTn, www.ncbi.nlm.nih.gov). According to BLASTn results, significant similarity was observed between both databases, with similarity values in the range of 96.21-99.79\% (Table 4). In accordance with findings of Drancourt et al. (2000), the bacteria were classified into the same genus when similarity values were $>99 \%$. For similarity values $<97 \%$, the bacteria were assigned into the same genus. As shown in Table 2, the identification process classified 15 LAB strains into six species, including Enterococcus faecium, E. faecalis, E. casseliflavus, Leuconostoc mesenteroides, Lactococcus lactis, and Enterococcus sp. Among 15 LAB strains, F2IS1 strain was identified as E. faecium, while both F2IS2 and F6IS1 strains were identified as E. faecalis. LAB strains F4IS4, F4IS5, F6IS4, F6IS5, F14IS5, and F14IS6 could be classified as E. casseliflavus. Strains F6IS2, F6IS3, F14IS4, and F14IS7 belonged to Enterococcus sp. Further, the strains F14IS1 and F14IS3 were identified as $L$. mesenteroides and L. lactis, respectively.

Evaluation of diversity of LAB species isolated from the samples collected during the production of ubi karet busuk showed the dominance of E. casseliflavus. Among the isolated strains, $40 \%$ of strains belonged to $E$. casseliflavus, followed by Enterococcus sp. (26.67\%) and E. faecalis $(13.33 \%)$. In comparison to these, very few LAB strains $(6.67 \%)$ were categorized as E. faecium, $L$. mesenteroides and L. lactis. These results were quite contrasting as compared to previous reports. In a previous study, E. casseliflavus was isolated from the intestinal tract of healthy rainbow trout (Oncorhynchus mykiss). E. casseliflavus was reported to display probiotic properties, such that the administration of E. casseliflavus to fish improved their resistance against Streptococcus iniae via immunomodulatory mechanisms. The study reported a significant increase in serum levels of lysozyme and $\mathrm{IgM}$ upon E. casseliflavus administration (Safari et al. 2016). Several other studies reported isolation of E. casseliflavus from a variety of food sources, including curd and sausage samples. These studies reported the production of bacteriocins by this strain. Use of E. casseliflavus inhibited the growth of Listeria monocytogenes and Pseudomonas aeruginosa, highlighting its suitability to be used as a food bio-preservative (Esposti et al. 2018; Indira et al. 2018). In a recent study, $\mathrm{Ng}$ et al. (2020) provided evidence for the isolation of $E$. faecium strains from a variety of food products and organic waste. These results further suggested that this bacterial strain might aid in the development of antimicrobials to inhibit the growth of Streptococcus mutans and Candida albicans.

Additionally, several other LAB species, including $E$. faecalis, L. mesenteroides, and L. lactis have been successfully utilized in the fermentation of milk to produce functional drinks containing bioactive and antimicrobial compounds (Borges et al. 2019; Graham et al. 2019; Bragason et al. 2020). Use of L. mesenteroides during fermentation of milk resulted in the production of a functional drink endowed with antimicrobial activity against Listeria monocytogenes. This functional drink also contained bioactive compounds in the form of conjugated linoleic acid (CLA), which were found to be useful in preventing and inhibiting various cardiovascular diseases (Borges et al. 2019). In a recent study, Graham et al. (2019) discovered that E. faecalis could ferment milk, resulting in products rich in phenolic compounds. These products displayed antioxidant activity and inhibited enzymatic activity of angiotensin-converting enzyme (ACE) and $\alpha$-glucosidase. Interestingly, both these enzymes are known to be associated with hypertension and hyperglycemia. In another study, Bragason et al. (2020) found that L. lactis could also catalyze the fermentation of milk, and the resulting products inhibited the growth of three pathogenic bacteria, namely Salmonella typhimurium, Klebsiella pneumonia, and Escherichia coli O157:H7.

In the present study, phylogenetic analysis was performed using the maximum likelihood method based on 16S rRNA gene sequences of bacteria. This method allows precise determination of the evolutionary history and relationships among bacterial species (Woese 1987). Following this, the sequencing data for each LAB strain was constructed using MEGA X software, while ClustalW was used for sequence alignment. ClustalW alignment is basically aimed at arranging each sequence in a homologous position. Gregory et al. (2008) previously proposed that the selection of one or more outgroups by the distance method could possibly help in localizing/identifying the root of the phylogenetic tree. In the present analysis, Escherichia coli U 5/41 strain was selected and used as an outgroup.

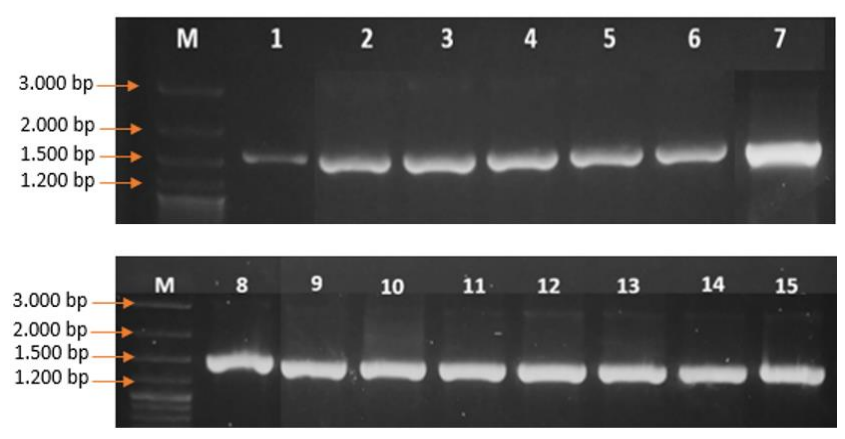

Figure 1. Results for PCR amplification of LAB strains isolated from indigenous cassava, performed using primers $27 \mathrm{~F}$ and 1492R. M: Marker DNA 100-300 bp; 1: F14IS1 strain, 2: F14IS3 strain, 3: F14IS4 strain; 4: F14IS5 strain; 5: F14IS6 strain; 6: F14IS7 strain; 7: F4IS4 strain; 8: F2IS2 strain; 9: F6IS2 strain; 10: F6IS3 strain; 11: F6IS4 strain; 12: F6IS5 strain; 13: F2IS1 strain; 14: F4IS5 strain; and 15: F6IS1 strain. 
Table 4. BLASTn results for LAB strains isolated from ubi karet busuk

\begin{tabular}{|c|c|c|c|c|}
\hline Strain & Species of LAB homolog & $\begin{array}{c}\text { Identity } \\
(\%)\end{array}$ & $\begin{array}{c}\text { Accession } \\
\text { number }\end{array}$ & Isolate sources \\
\hline \multirow[t]{3}{*}{ F2IS1 } & Enterococcus faecium strain DSM 20477 & 99.58 & NR_114742.1 & Culture collection \\
\hline & Enterococcus faecium strain NBRC 100486 & 99.51 & NR_113904.1 & Culture collection \\
\hline & Enterococcus faecium strain ATCC 19434 & 99.51 & NR_115764.1 & Culture collection \\
\hline \multirow[t]{3}{*}{ F2IS2 } & Enterococcus faecalis strain NBRC 10048 & 99.65 & NR_113901.1 & Culture collection \\
\hline & Enterococcus faecalis strain ATCC 19433 & 99.59 & NR_115765.1 & Culture collection \\
\hline & Enterococcus faecalis strain LMG 7937 & 99.38 & NR_114782.1 & Culture collection \\
\hline \multirow[t]{3}{*}{ F4IS4 } & Enterococcus casseliflavus strain NBRC 100478 & 99.72 & NR_104560.1 & Plant material \\
\hline & Enterococcus casseliflavus strain NCIMB 11449 & 99.72 & NR_119280.1 & Culture collection \\
\hline & Enterococcus gallinarum strain LMG 13129 & 99.52 & NR_104559.2 & Chicken intestine \\
\hline \multirow[t]{3}{*}{ F4IS5 } & Enterococcus casseliflavus strain NBRC 100478 & 99.72 & NR_104560.1 & Plant material \\
\hline & Enterococcus casseliflavus strain NCIMB 11449 & 99.72 & NR_119280.1 & Culture collection \\
\hline & Enterococcus gallinarum strain LMG 13129 & 99.52 & NR_104559.2 & Chicken intestine \\
\hline \multirow[t]{3}{*}{ F6IS1 } & Enterococcus faecalis strain NBRC 100480 & 99.50 & NR_113901.1 & Culture collection \\
\hline & Enterococcus faecalis strain ATCC 19433 & 99.45 & NR_115765.1 & Culture collection \\
\hline & Enterococcus faecalis strain LMG 7937 & 99.24 & NR_114782.1 & Culture collection \\
\hline \multirow[t]{3}{*}{ F6IS2 } & Enterococcus casseliflavus strain NCIMB 11449 & 96.32 & NR_119280.1 & Culture collection \\
\hline & Enterococcus casseliflavus strain NBRC 100478 & 96.25 & NR_104560.1 & Plant material \\
\hline & Enterococcus gallinarum strain LMG 13129 & 96.21 & NR_104559.2 & Chicken intestine \\
\hline \multirow[t]{3}{*}{ F6IS3 } & Enterococcus casseliflavus strain NBRC 100478 & 98.93 & NR_104560.1 & Plant material \\
\hline & Enterococcus casseliflavus strain NCIMB 11449 & 98.93 & NR_119280.1 & Culture collection \\
\hline & Enterococcus gallinarum strain LMG 13129 & 98.68 & NR_104559.2 & Chicken intestine \\
\hline \multirow[t]{3}{*}{ F6IS4 } & Enterococcus casseliflavus strain NBRC 100478 & 98.31 & NR_104560.1 & Plant material \\
\hline & Enterococcus casseliflavus strain NCIMB 11449 & 98.31 & NR_119280.1 & Culture collection \\
\hline & Enterococcus gallinarum strain LMG 13129 & 98.01 & NR_104559.2 & Chicken intestine \\
\hline \multirow[t]{3}{*}{ F6IS5 } & Enterococcus casseliflavus strain NBRC 100478 & 98.57 & NR_104560.1 & Plant material \\
\hline & Enterococcus casseliflavus strain NCIMB 11449 & 98.57 & NR_119280.1 & Culture collection \\
\hline & Enterococcus gallinarum strain LMG 13129 & 98.33 & NR_104559.2 & Chicken intestine \\
\hline \multirow[t]{3}{*}{ F14IS1 } & Leuconostoc mesenteroides strain ATCC 8293 & 99.59 & NR_074957.1 & Fermented olives \\
\hline & Leuconostoc mesenteroides subsp. dextranicum strain NBRC 100495 & 99.59 & NR_113911.1 & Culture collection \\
\hline & Leuconostoc mesenteroides strain JCM 6124 & 99.59 & NR_113251.1 & Fermenting olives \\
\hline \multirow[t]{3}{*}{ F14IS3 } & Lactococcus lactis Strain NBRC 100933 & 99.72 & NR_113960.1 & Culture collection \\
\hline & Lactococcus lactis Strain NCDO 604 & 99.72 & NR_040955.1 & Culture collection \\
\hline & Lactococcus lactis subsp. hordniae strain NBRC 100931 & 99.59 & NR_113958.1 & $\begin{array}{l}\text { Leafhopper, Hordnia } \\
\text { circellata }\end{array}$ \\
\hline \multirow[t]{3}{*}{ F14IS4 } & Enterococcus casseliflavus strain NCIMB 11449 & 97.18 & NR_119280.1 & Culture collection \\
\hline & Enterococcus casseliflavus strain NBRC 100478 & 97.11 & NR_104560.1 & Plant material \\
\hline & Enterococcus gallinarum strain LMG 13129 & 96.98 & NR_104559.2 & Chicken intestine \\
\hline \multirow[t]{3}{*}{ F14IS5 } & Enterococcus casseliflavus strain NBRC 100478 & 99.79 & NR_104560.1 & Plant material \\
\hline & Enterococcus casseliflavus strain NCIMB 11449 & 99.79 & NR_119280.1 & Culture collection \\
\hline & Enterococcus gallinarum strain LMG 13129 & 99.59 & NR_104559.2 & Chicken intestine \\
\hline \multirow[t]{3}{*}{ F14IS6 } & Enterococcus casseliflavus strain NCIMB 11449 & 99.72 & NR_119280.1 & Culture collection \\
\hline & Enterococcus casseliflavus strain NBRC 100478 & 99.65 & NR_104560.1 & Plant material \\
\hline & Enterococcus gallinarum strain LMG 13129 & 99.52 & NR_104559.2 & Chicken intestine \\
\hline \multirow[t]{3}{*}{ F14IS7 } & Enterococcus casseliflavus strain NCIMB 11449 & 97.37 & NR_119280.1 & Culture collection \\
\hline & Enterococcus casseliflavus strain NBRC 100478 & 97.30 & NR_104560.1 & Plant material \\
\hline & Enterococcus gallinarum strain LMG 13129 & 97.16 & NR_104559.2 & Chicken intestine \\
\hline
\end{tabular}

Further, Tamura-Nei + Gamma (TN93+G) model was chosen as the optimal phylogenetic parameter for transition rates among sites, based on the Bayesian information criterion. In particular, TN93 + G model was chosen owing to the lowest values for Bayesian information criterion (BIC) and Akaike information criterion (AICc) (Nishimaki and Sato 2019). This Maximum likelihood analysis was performed on the basis of the nucleotide substitution model, involving partial elimination of gaps or missing data.
Therefore, bootstrap analysis of 1000 replicates was performed to evaluate the phylogenetic tree topology. The use of bootstrap was particularly critical as it measured the reliability of phylogeny tree, resulting in trees with variable truth support. According to Holmes et al., a very similar sequence could be placed as a neighbor outside of the branches and connected in a common branch (Holmes 2003). As shown in Figure 2, 15 LAB strains isolated from the indigenous cassava were clustered into five clades of $E$. faecium, E. faecalis, E. casseliflavus, L. lactis, and $L$. mesenteroides with bootstrap values $>70 \%$. 


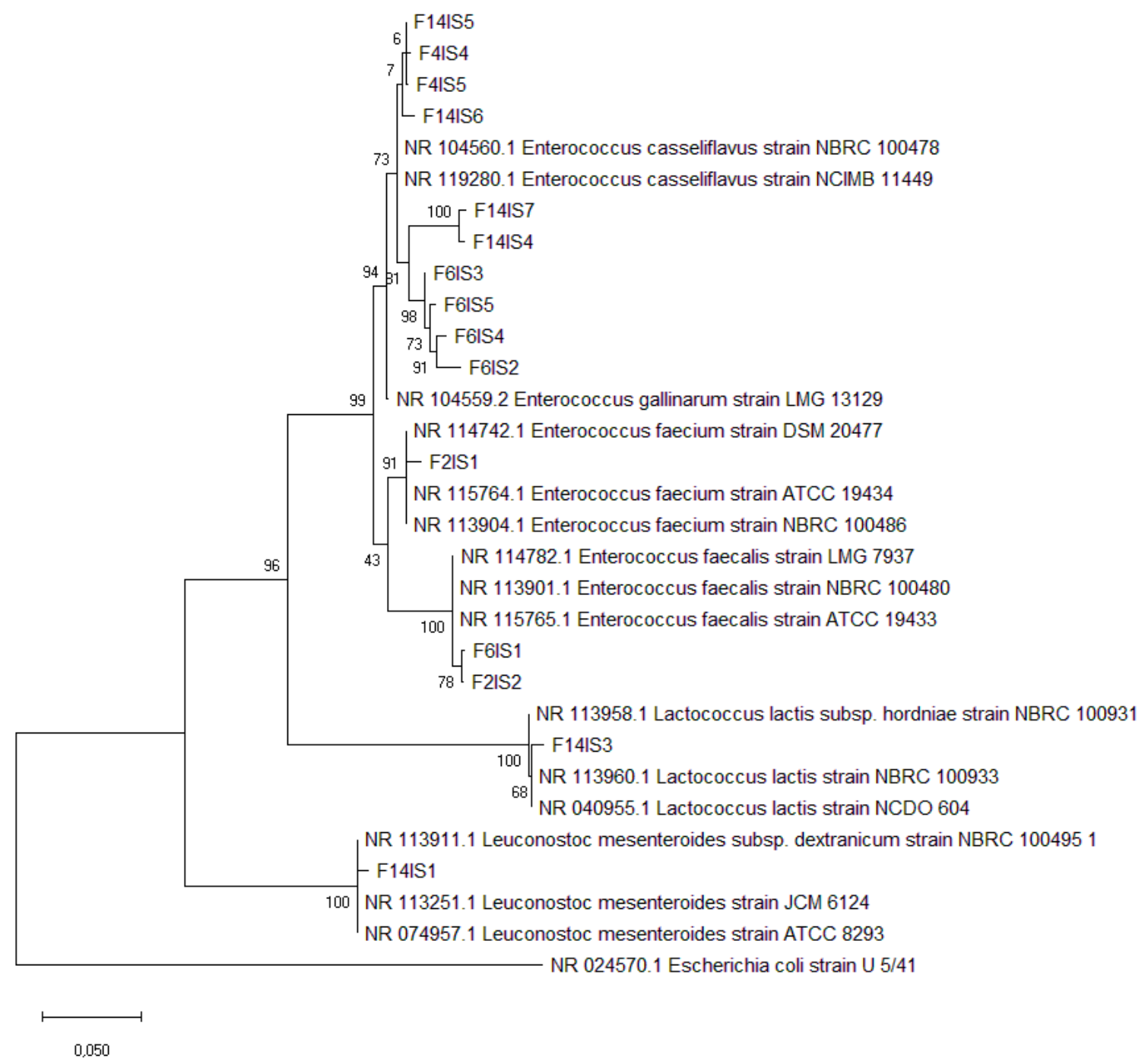

Figure 2. Phylogenetic tree showing the relationship between 15 LAB strains and 16S rRNA gene sequences obtained from NCBI database using Maximum Likelihood analysis with bootstrap of 1000 replication

In $91 \%$ of the bootstrap replications, F2IS1 strain was located in the same cluster and appeared as a descendant to E. faecium strain DSM 20477, E. faecium strain NBRC 100486, and E. faecium strain ATCC 19434. The results of the analysis were in accordance with the BLASTn results, which showed that the F2S1 strain was characterized by an identity score of 99.51-99.58 with E. faecium strain. In comparison to this, F2IS2 and F6IS1 strains clustered with E. faecalis strain LMG 7937, E. faecalis strain NBRC 100480, and E. faecalis strain ATCC 19433, with bootstrap value of $100 \%$. These findings were consistent with the results of BLASTn analysis, where these strains showed identity scores in the range of 99.65-99-99.24 with $E$. faecalis. LAB strains including F4IS4, F4IS5, F6IS2, F6IS3, F6IS4, F6IS5, F14IS4, F14IS5, F14IS6, and F14IS7 were located as the closest neighbors to E. casseliflavus strain NBRC 100478 and E. casseliflavus strain NCIMB 11449 , with bootstrap value of 73 . The results of this phylogenetic analysis were found to be in concordance with BLASTn results, where the strains displayed identity score values in the range of $96-99 \%$ with E. casseliflavus.
The LAB strains F14IS5 and F14IS6 constituted one clade and showed identity value of $99 \%$ with E. casseliflavus strains. Similarly, LAB strains F6IS3, F6IS4, and F6IS5 formed one clade and were characterized by an identity value of $98 \%$ with E. casseliflavus strains. Further, F14IS4 and F14IS7 strains produced one clade and showed identity value of $97 \%$ with $E$. casseliflavus strain. In comparison to these, F6IS2 strain showed lowest identity value of $96 \%$ with $E$. casseliflavus strain.

The results of the analysis showed that F14IS3 strain clearly clustered within the clade of $L$. lactis subsp. hordniae strain NBRC 100931, L. lactis strain NBRC 100933, and L. lactis strain NCDO 604, with a bootstrap value of $100 \%$. In comparison to this, F14IS1 strain clustered with $L$. mesenteroides subps. Dextranicum strain NBRC 100495, L. mesenteroides strain JCM 6124, and $L$. mesenteroides strain ATCC 8293, with a bootstrap value of $100 \%$. The phylogenetic analysis for F14IS3 and F14IS1 strains was found to be in concordance with the findings of BLASTn, where identity scores of $99.72 \%$ and $99.59 \%$ were recorded with $L$. lactis and $L$. mesenteroides, respectively. 
Table 5. Comparison of $\beta$-glucosidase and tannase activity of LAB strains isolated during fermentation of indigenous cassava produced in Sumba, Indonesia

\begin{tabular}{llcc}
\hline \multirow{2}{*}{ Strain } & \multicolumn{1}{c}{ Species } & \multicolumn{2}{c}{ Enzyme activity $(\mathbf{U} / \mathbf{m L})$} \\
\cline { 3 - 4 } & & $\boldsymbol{\beta}$-glucosidase & Tannase \\
\hline F2IS1 & Enterococcus faecium & 6.23 & - \\
F2IS2 & Enterococcus faecalis & 5.23 & 35.45 \\
F4IS4 & Enterococcus casseliflavus & - & - \\
F4IS5 & Enterococcus casseliflavus & 4.29 & - \\
F6IS1 & Enterococcus faecalis & 5.12 & 38.23 \\
F6IS2 & Enterococcus sp. & - & 25.79 \\
F6IS3 & Enterococcus sp. & 4.33 & - \\
F6IS4 & Enterococcus casseliflavus & 4.35 & - \\
F6IS5 & Enterococcus casseliflavus & - & - \\
F14IS1 & Leuconostoc mesenteroides & 7.82 & - \\
F14IS3 & Lactococcus lactis & 7.13 & - \\
F14IS4 & Enterococcus sp. & - & - \\
F14IS5 & Enterococcus casseliflavus & 4.31 & - \\
F14IS6 & Enterococcus casseliflavus & 4.15 & - \\
F14IS7 & Enterococcus sp. & - & - \\
\hline
\end{tabular}

\section{$\beta$-glucosidase and tannase activity of LAB strains}

The presence of $\beta$-glucosidase and tannase activity was evaluated in $15 \mathrm{LAB}$ strains isolated from ubi karet busuk. The results for the enzymatic activity are summarized in Table 5. Among these, $10 \mathrm{LAB}$ strains, including $E$. faecium F2IS1, E. faecalis F2IS2, E. casseliflavus F4IS5, E. faecalis F6IS1, Enterococcus sp. F6IS3, E. casseliflavus F6IS4, L. mesenteroides F14IS1, L. lactis F14IS3, E. casseliflavus F14IS5, and E. casseliflavus F14IS6 showed $\beta$-glucosidase activity in the range of 7.13-4.15 U/mL. In particular, L. lactis F14IS3 displayed highest $\beta$-glucosidase activity, while E. casseliflavus F14IS6 showed lowest $\beta$-glucosidase activity. Additionally, E. faecalis F2IS2 and E. faecalis F6IS1 also produced tannase, with enzyme activity of 34.45 and $38.23 \mathrm{U} / \mathrm{mL}$, respectively. In comparison to these, Enterococcus sp. F6IS2H exclusively produced tannase, with enzyme activity of $25.79 \mathrm{U} / \mathrm{mL}$. Previous studies reported $\beta$-glucosidase activity of 24.5 , 3.96, 6.72, and $2.7 \mathrm{U} / \mathrm{mL}$ for $\mathrm{LAB}$ species Lactobacillus sp., L. acidophilus, L. rhamnosus, and L. mesenteroides, respectively (Strahsburger et al. 2017; Liu et al. 2018; Zhu et al. 2019). In comparison to this, tannase activity of 6.26 , 32.58 , and $4.2 \mathrm{U} / \mathrm{mL}$ have been previously reported for LAB species $L$. plantarum isolated from pickled cabbage, E. faecalis isolated from goat feces, and E. cloacae isolated from gut of mole crickets (Gryllotalpa krishnani), respectively (Rodríguez et al., 2008; Goel et al. 2011; Govindarajan et al. 2019). All these findings suggested the suitability of $\beta$-glucosidase and tannase producing LAB strains to be utilized as a starter in the fermentation of cassava and other substrates such as vegetables, fruits, and legumes (Sáez et al. 2017; Li et al. 2018; Liu et al. 2018; Zhu et al. 2019). Furthermore, these two enzymes find wide applications in food, beverage, and animal feed industries. In particular, these enzymes can be utilized in the clarification and de-bittering of refreshing drinks, removal of anti-nutritional factors (ANF), and production of bioactive metabolites in animal feed and food industries (Yao et al. 2014; Aharwar and Parihar 2018).

In the present study, $15 \mathrm{LAB}$ strains were isolated during the fermentation of ubi karet busuk, the most famous traditional fermented cassava produced in Sumba Island, East Nusa Tenggara. Homofermentative trait was found to be predominating among these LAB strains, where $93.33 \%$ strains displayed homofermentative trait, while $6.73 \%$ strains were associated with heterofermentative characteristic. According to BLASTn and phylogenetic analysis, these $\mathrm{LAB}$ strains were classified into six species, namely E. faecium, E. faecalis, E. casseliflavus, L. mesenteroides, L. lactis, and Enterococcus sp. In particular, $40 \%$ of these LAB strains were characterized as E. casseliflavus, followed by 26.67 $\%$ identified as Enterococcus sp., and $13.33 \%$ as E. faecalis. In comparison to these, only $6.67 \%$ of strains were classified as E. faecium, L. mesenteroides, and L. lactis. Interestingly, $\beta$-glucosidase activity was detected in 10 LAB strains, with L. lactis F14IS3 displaying highest $\beta$-glucosidase activity of $7.13 \mathrm{U} / \mathrm{mL}$. Among these $10 \mathrm{LAB}$ strains, F2IS2 and F6IS1 strains also expressed tannase, with F6IS1 displaying highest enzyme activity of 38.23 $\mathrm{U} / \mathrm{mL}$. Thus, the present study results provided evidence for the production of $\beta$-glucosidase and tannase by the LAB strains isolated from ubi karet busuk, highlighting their suitability to be utilized as a starter in the fermentation of cassava and other substrates like vegetables, fruits, and legumes. These strains can also be utilized in various processes in the animal feed, food, and beverage industries.

\section{ACKNOWLEDGEMENTS}

The present study was financially supported by Ministry of Research and Technology-Directorate General of Higher Education, Ministry of National, Indonesia through PTM (contract number: 6/AMD/E1/KP.PTNBH/2020 and 3010/UN1.DITLIT/DIT-LIT/PT/2020).

\section{REFERENCES}

Acebrón I, Plaza-Vinuesa L, de las Rivas B, Muñoz R, Cumella J, Sánchez-Sancho F, Mancheño JM. 2017. Structural basis of the substrate specificity and instability in solution of a glycosidase from Lactobacillus plantarum. BBA-Proteins Proteom 1865: 1227-1236 DOI: 10.1016/j.bbapap.2017.07.007.

Aharwar A, Parihar DK. 2018. Tannases: Production, properties, applications. Biocatal Agric Biotechnol 15: 322-334. DOI: 10.1016/j.bcab.2018.07.005.

Axelsson L. 2004. Lactic acid bacteria: Classification and physiology. In Salminen S, Wright AV, Ouwehand A (eds). Lactic Acid Bacteria: Microbiological and Functional Aspects. $3^{\text {rd }}$ ed. Marcel Dekker Inc., New York.

Baruah J, Nath BK, Sharma R, Kumar S, Deka RC, Baruah DC, Kalita E. 2018. Recent trends in the pretreatment of lignocellulosic biomass for value-added products. Front Energy Res 6: 141. DOI: 10.3389/fenrg.2018.00141

Borges DO, Matsuo MM, Bogsan CSB, da Silva TF, Casarotti SN, Penna ALB. 2019. Leuconostoc mesenteroides subsp. mesenteroides SJRP55 reduces Listeria monocytogenes growth and impacts on fatty acids profile and conjugated linoleic acid content in fermented cream. LWT-Food Sci Technol 107: 264-271. DOI: 10.1016/j.lwt.2019.02.085. 
Bragason E, Berhe T, Dashe D, Sørensen KI, Guya ME, Hansen EB. 2020. Antimicrobial activity of novel Lactococcus lactis strain against Salmonella typhimurium DT12, Escherichia coli O157:H7 VT and Klebsiella pneumoniae in raw and pasteurised camel milk. Int Dairy J 111: 104832. DOI: 10.1016/j.idairyj.2020.104832. 104832.

Clarridge JE. 2004. Impact of $16 \mathrm{~S}$ rRNA gene sequence analysis for identification of bacteria on clinical microbiology and infectious diseases. Clin Microbiol Rev 17 (4): 840-862. DOI: 10.1128/CMR.17.4.840-862.2004.

Drancourt M, Bollet C, Carlioz A, Martelin R, Gayral J, Raoult D. 2000. 16S Ribosomal DNA sequence analysis of a large collection of environmental and clinical unidentifiable bacterial isolates. J Clin Microbiol 38 (10): 3623-3630. DOI: 10.1128/JCM.38.10.36233630.2000 .

de la Fuente B, Luz C, Puchol C, Meca G, Barba FJ. 2021. Evaluation of fermentation assisted by Lactobacillus brevis POM, and Lactobacillus plantarum (TR-7, TR-71, TR-14) on antioxidant compounds and organic acids of an orange juice-milk based beverage. Food Chem 343: 128414. DOI: 10.1016/j.foodchem.2020.128414.

Delpech P, Bornes S, Alaterre E, Bonnet M, Gagne G, Montel M, Delbes C. 2015. Staphylococcus aureus transcriptomic response to inhibition by $\mathrm{H}_{2} \mathrm{O}_{2}$-producing Lactococcus garvieae. Food Microbiol 51: 163 170. DOI: 10.1016/j.fm.2015.05.014.

de Oliveira RA, Eduardo AKC, Vaz Rossell RM, Filho. 2018. Challenges and opportunities in lactic acid bioprocess design-from economic to production aspects. Biochem Eng J 15: 219-239 DOI: 10.1016/j.bej.2018.03.003

Donkor ON, Shah NP. 2008. Production of $\beta$-glucosidase and hydrolysis of isoflavone phytoestrogens by Lactobacillus acidophilus, Bifidobacterium lactis, and Lactobacillus casei in soymilk. J Food Sci 73: M15-M20. DOI: 10.1111/j.1750-3841.2007.00547.x

Esposti MD, Toselli M, Sabia C, Messi P, de Niederhäusern S, Bondi M, Iseppi R. 2018. Effectiveness of polymeric coated films containing bacteriocin-producer living bacteria for Listeria monocytogenes control under simulated cold chain break. Food Microbiol 76: 173 179. DOI: $10.1016 /$ j.fm.2018.05.005

Fabien J. Cousin FB, Le Guellec R, Chagnot C, Goux D, Dalmasso M, Laplace J-M, Cretenet M. 2019. Oenococcus sicerae sp. nov., isolated from French cider. Syst Appl Microbiol 42: 302-308. DOI: 10.1016/j.syapm.2018.12.006.

Freire AL, Ramos CL, Schwan RF. 2015. Microbiological and chemical parameters during cassava based-substrate fermentation using potential starter cultures of lactic acid bacteria and yeast. Food Res Int 76: 787-795. DOI: 10.1016/j.foodres.2015.07.041.

Fusco V, Quero GM, Cho G-S, Kabisch J, Meske D. Neve H, Bockelmann W, Franz CMAP. 2015. The genus Weissella: taxonomy, ecology and biotechnological potential. Front Microbiol 6 (155). DOI: 10.3389/fmicb.2015.00155

Goel G, Kumar A, Beniwal V, Raghava M, Puniyaa AK, Singh K. 2011. Degradation of tannic acid and purification and characterization of tannase from Enterococcus faecalis. Intl Biodeter Biodegr 65: 1061065. DOI: 10.1007/s00449-014-1208-3.

González-Arenzana L, López R, Portu J, Santamaría P, Garde-Cerdán T, López-Alfaro I. 2014. Molecular analysis of Oenococcus oeni and the relationships among and between commercial and autochthonous strains. J Biosci Bioeng 118 (3): 272-276. DOI: 10.1016/j.jbiosc.2014.02.013

Govindarajan RK, Mathivanan K, Rameshkumar N, Shyu, DJH Krishnan M, Kayalvizhi N. 2019. Purification, structural characterization and biotechnological potential of tannase enzyme produced by Enterobacter cloacae strain 41. Process Biochem 77: 37-47. DOI: 10.1016/j.procbio.2018.10.013.

Graham K, Rea R, Simpson P, Stack H. 2019. Enterococcus faecalis milk fermentates display antioxidant properties and inhibitory activity towards key enzymes linked to hypertension and hyperglycaemia. J Funct Foods 58: 292-300. DOI: 10.1016/j.jff.2019.04.052.

Gregory TR. 2008. Understanding evolutionary trees. Evo Edu Outreach 1:121-137. DOI 10.1007/s12052-008-0035-x.

Grewal J, Khare S. 2018. One-pot bioprocess for lactic acid production from lignocellulosic agro-wastes by using ionic liquid stable Lactobacillus brevis. Bioresour Technol 251: 268-273. DOI: 10.1016/j.biortech.2017.12.056.

Hassan SE-D, Abdel-Rahman MA, Roushdy MM, Azab MS, Gaber MA 2019. Effective biorefinery approach for lactic acid production based on co-fermentation of mixed organic wastes by Enterococcus durans
BP130. Biocataly Agric Biotechnol 20: 101203. DOI: 10.1016/j.bcab.2019.101203

Hatti-Kaul R, Chen L, Dishisha T, Enshasy HE. 2018. Lactic acid bacteria: From starter cultures to producers of chemicals. FEMS Microbiol Lett 365 (20). DOI: 10.1093/femsle/fny213.

Holmes S. 2003. Bootstrapping phylogenetic trees: Theory and methods. Statist Sci 18 (2): 241-255. DOI: 10.1214/ss/1063994979.

Huang Z-R, Hong J-L, Xua J-X, Lia L, Wei-Ling Guo, W-L, Pan Y-Y, Chen S-J, Bai W-D, Rao PF, Ni L, Zhao L-N, Liu B, Lv X-C. 2018. Exploring core functional microbiota responsible for the production of volatile flavour during the traditional brewing of Wuyi Hong $\mathrm{Qu}$ glutinous rice wine. Food Microbiol 76: 487-496. DOI: 10.1016/j.fm.2018.07.014.

Indira M, Venkateswarulu TC, Prabhakar KV, Peele KA, Krupanidhi S. 2018. Isolation and characterization of bacteriocin producing Enterococcus casseliflavus and its antagonistic effect on Pseudomonas aeruginosa. Karbala Intl J Modern Sci 4: 361-368. DOI: 10.1016/j.kijoms.2018.09.002.

Kanpiengjai A, Unban K, Nguyen T, Haltrich D, Khanongnuch C. 2019. Expression and biochemical characterization of a new alkaline tannase from Lactobacillus pentosus. Protein Expr Purif 157: 36-41. DOI: 10.1016/j.pep.2019.01.005.

Kimura M. 1980. A simple method for estimating evolutionary rates of base substitutions through comparative studies of nucleotide sequences. J Mol Evol 16(2):111-120. DOI: 10.1007/BF01731581.

Kulla PDK, Retnaningrum E. 2019. Biochemical and microbial change in food fermentation 'ubi karet busuk' Sumba, East Nusa Tenggara, Indonesia. Proceedings of the $20196^{\text {th }}$ International Conference on Bioinformatics Research and Applications (ICBRA 2019). Seoul, South Korea. 19 December 2019-21 December 2019, 3383801: 24-27 DOI: $10.1145 / 3383783.3383801$.

Kumar S, Stecher G, Li M, Knyaz C, Tamura K. 2018. MEGA X: Molecular Evolutionary Genetics Analysis across Computing Platforms. Mol Biol Evol 35 (6): 1547-1549. DOI: 10.1093/molbev/msy096.

Langa S, Martín-Cabrejas I, Montiel R, Peiroten A, Arques JL, Medina M. 2018. Protective effect of reuterin-producing Lactobacillus reuteri against Listeria monocytogenes and Escherichia coli $\mathrm{O} 157: \mathrm{H} 7$ in semi-hard cheese. Food Control 84: 284-289. DOI: 10.1016/j.foodcont.2017.08.004.

Li R, Fu G, Liu C, McClements DJ, Wan Y, Wang S, Liu T. 2018. Tannase immobilisation by amino-functionalised magnetic $\mathrm{Fe}_{3} \mathrm{O}_{4}{ }^{-}$ chitosan nanoparticles and its application in tea infusion. I J Biol Macromol 114: 1134-1143 DOI: 10.1016/j.ijbiomac.2018.03.077.

Liu W-S, Yang C-Y, Fang TJ. 2018. Strategic ultrasound-induced stress response of lactic acid bacteria on enhancement of $\beta$-glucosidase activity for bioconversion of isoflavones in soymilk. J Microbiol Methods 148: 145-150. DOI: 10.1016/j.mimet.2018.04.006.

Lopez-Gomez JP, Latorre-Sanchez m, Unger P, Schneider R, Coll Lozano C, Venus J. 2019. Assessing the organic fraction of municipal solid wastes for the production of lactic acid. Biochem Eng J 150: 107251. DOI: $10.1016 /$ j.bej.2019.107251.

Mondal KC, Banerjee D, Jana M, Pati BR. 2001. Colorimetric assay method for determination of the tannin acyl hydrolase (EC 3.1.1.20) $\begin{array}{llll}\text { activity. Anal Biochem } 295 & \text { (2): 168-171. DOI: }\end{array}$ 10.1006/abio.2001.5185.

Nambisan B. 2011. Strategies for elimination of cyanogens from cassava for reducing toxicity and improving food safety. Food ChemToxicol 49: 690-693. DOI: 10.1016/j.fct.2010.10.035.

Ng ZJ, Zarin MA, Lee CK, Phapugrangkul P, Tan, JS. 2020. Isolation and characterization of Enterococcus faecium DSM 20477 with ability to secrete antimicrobial substance for the inhibition of oral pathogen Streptococcus mutans UKMCC 1019. Arch Oral Biol 110: 104617. DOI: 10.1016/j.archoralbio.2019.104617.

Nishimaki T, Sato K. 2019. An Extension of the Kimura two-parameter model to the natural evolutionary process. J Mol Evol 87 (1): 60-67. DOI: $10.1007 / \mathrm{s} 00239-018-9885-1$

Nurhikmayani R, Daryono BS, Retnaningrum E. 2019. Isolation and molecular identification of antimicrobial-producing Lactic Acid Bacteria from chao, South Sulawesi (Indonesia) fermented fish product. Biodiversitas 20 (4): 1063-1068. DOI: 10.13057/biodiv/d200418.

Otieno DO, Ashton JF, Shah NP. 2006. Evaluation of enzymic potential for biotransformation of isoflavone phytoestrogen in soymilk by Bifidobacterium animalis, Lactobacillus acidophilus and 
Lactobacillus casei. Food Res Intl 39: 394-407. DOI: 10.1016/j.foodres.2005.08.010

Retnaningrum E, Yossi T, Nur'azizah R, Sapalina F, Kulla PDK. 2020. Characterization of a bacteriocin as bio preservative synthesized by indigenous lactic acid bacteria from dadih soya traditional product used in West Sumatra, Indonesia. Biodiversitas 21 (9): 4192-4198. DOI: $10.13057 /$ biodiv/d210933.

Rodríguez H, de las Rivas B, Gómez-Cordovés C, Muñoz R. 2008. Characterization of tannase activity in cell-free extracts of Lactobacillus plantarum CECT $748^{\mathrm{T}}$. Intl J Food Microbiol 121: 9298. DOI: 10.1016/j.ijfoodmicro.2007.11.002.

Sáez GD, Hébert EM, Saavedra L, Zárate G. 2017. Molecular identification and technological characterization of lactic acid bacteria isolated from fermented kidney beans flours (Phaseolus vulgaris L. and $P$. coccineus) in northwestern Argentina. Food Res Intl 102: 605 615. DOI: 10.1016/j.foodres.2017.09.042.

Safari R, Adel M,. Lazado CC, Caipang CMA, Dadar M. 2016. Hostderived probiotics Enterococcus casseliflavus improves resistance against Streptococcus iniae infection in rainbow trout (Oncorhynchus mykiss) via immunomodulation. Fish Shellfish Immunol 52: 198-205. DOI: 10.1016/j.fsi.2016.03.020.

Sanger F, Nicklen S, Coulson AR. 1977. DNA sequencing with chain terminating inhibitors Proc Nati Acad Sci USA 74: 12: 5463-5467. DOI: 10.1073/pnas.74.12.5463

Sapalina F, Retnaningrum E. 2020. Molecular characterization of lactic acid bacteria producing edible biofilm isolated from kimchi. Biodiversitas 21 (3): 962-968. DOI: 10.13057/biodiv/d210315.

Sauer M, Russmayer H, Grabherr R, Peterbauer CK, Marx H. 2017. The efficient clade: lactic acid bacteria for industrial chemical production.

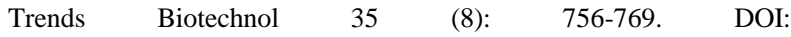
10.1016/j.tibtech.2017.05.002.

Shang Y, Cao H, Ma L, Zhang C, Ma F, Wang C, Ni X, Lee W, Wei Z. 2019. Effect of lactic acid bacteria fermentation on tannins removal in Xuan Mugua fuits. Food Chem 274: 118-122. DOI: 10.1016/j.foodchem.2018.08.120

Sharma S, Bhat TK, Dawra RK. 2000. A spectrophotometric method for assay of tannase using rhodanine. Anal Biochem 279: 85-89. DOI: 10.1006/abio.1999.4405.

Strahsburger E, de Lacey AML, Marotti I, DiGioia D, Biavati B, Dinelli G. 2017. In vivo assay to identify bacteria with $\beta$-glucosidase activity. Electron J Biotechnol 30: 83-87. DOI: 10.1016/j.ejbt.2017.08.010.

Vilanova L, Viñas I, Torres R, Usall J, Buron-Moles G, Teixidó N. 2014 Acidification of apple and orange hosts by Penicillium digitatum and Penicillium expansum. Intl J Food Microbiol 178: 39-49. DOI: 10.1016/j.ijfoodmicro.2014.02.022.

Weagant SD, Feng P, Stanfield JT. 2001. Yersinia enterocolitica and Yersinia pseudotuberculosis. In: Bacteriological Analytical Manual. US Food and Drug Administration, Center for Food Safety and Applied. Nutrition, Washington, DC.

Woese CR. 1987. Bacterial evolution. Microbiol Rev 51 (2): 221-271.

Yao J, Guo GS, Ren GH, Liu YH. 2014. Production, characterization and applications of tannase. J Mol Catal B Enzym 101: 137-147. DOI: 10.1016/j.molcatb.2013.11.018.

Zhu Y, Wang Z, Zhang L. 2019. Optimization of lactic acid fermentation conditions for fermented tofu whey beverage with high-isoflavone aglycones. LWT-Food Sci Technol 111: 211-217. DOI: 10.1016/j.1wt.2019.05.021. 